\title{
A Cross-cultural Study of Compliment Response Strategy between Sorani Kurdish and Australian English
}

\author{
Baida'a Abdul Kareem Rasheed
}

College of Languages and Human sciences, University of Garmian, Kurdistan Region, Iraq Baidaa.rasheed@yahoo.co.uk

\begin{abstract}
The speech act of compliment is one of the neglected areas of research in the Kurdish context. In this paper, the researcher investigates whether Kurdish speaker affected by their cultural norms - in particular by the politeness system-in responding to compliments compared to Australian interlocutors. Compliment responses were elicited - through a Discourse Completion Task-from 10 Kurdish participants (6 males and 4 females): all Kurdish participants were postgraduate students at the University of Nottingham in 2014 and the data for Australian participants were taken from the Tarabi and Beuzeville (2012) study. The Australian participants consisted of 5 females and 5 males.

The Kurdish responses were categorised according to Herbert's (1986) taxonomy and the results show that although there are similarities in the choice of compliment response types by, both groups. However, there are still some differences. This paper aims to contribute to the knowledge of potential areas for miscommunications in intercultural interactions, and also to find ways to improve language teaching and learning.
\end{abstract}

Keywords: compliment responses; Kurdish; Australian English; intercultural communication.

\section{Introduction}

Communication with others is one of the social activities, which is performed by people either verbally or non-verbally using language. Using language to perform an action is known as speech acts (Austin, 1962). Different cultural values are mirrored through different speech acts; if people fail to interpret them in accordance to the specified cultural norm, it may lead to misinterpretation and intercultural miscommunication would occur (Cohen,1996). Compliment is one of the speech acts through which the cultural values of a specific language are reflected (Manes, 1983). Despite the fact that compliment is considered as positive speech act, which is used by many to maintain solidarity with the listener, it might also be considered as a face threating act when they are used in a sarcastic way or used for criticizing (Yu, 2003).
415
acadj@garmian.edu.krd
Vol.5, No.4 (August, 2018) 
For a compliment to be perceived as a positive or a negative speech act, different factors need to be taken in to account such as cultural protocol, individual interpretation and the context in which they are delivered (Golato, 2005). Thus, if people fail to realize the sociolinguistic communication being followed in in other cultures, they might fail to respond to compliment in an appropriate way.

There is no doubt that investigating speech act behaviour; would assist in gaining some knowledge on each culture techniques of performing them and avoiding cultural misunderstanding. Therefore, examining this aspect of interaction can be valuable to our understanding of their nature. As Yu (2003) emphasized that, "Compliment responses are worthy of study because they are ubiquitous, yet frequently problematic speech acts. The fact that compliments are easily heard in everyday conversations indicates that responding to compliments is a common feature of discoursal activities" (p. 1687). Similarly, Yuan (2001) asserted that Compliment responses (CRs) are "worth studying because, like all speech acts, they can show us the rules of language use in a speech community" (273).

Compliment responses have been studied not only for varieties of English, for instance Wolfson (1983) for American English, Holmes (1988) for New Zealand English, and Creese (1991) for American English and British English, but also for other languages such as Chinese (Chang, 1988), Japanese (Daikuhara, 1986), and Syrian Arabic (Nelson et al, 1996). However, no empirical study on compliment responses in Kurdish culture has been located in the literature. Therefore, this study is an attempt to shed some lights on the norms and patterns of compliment responses in Kurdish community and to contrast them with those of Australian English speakers on cross-cultural basis.

Further, this present study aims to identify the similarities and differences in the compliment response patterns by native Kurdish speakers and Australian speakers in terms of the frequency and from cross-cultural perspective. This study has also attempted to figure out whether the politeness maxim triggers certain compliment response pattern rather than others, so it is of importance to take those matters into consideration when responding to a compliment. This study also aims at considering the following research questions: Do Kurdish and Australian native speakers use different compliment response pattern? If yes, How? And do the compliment response strategies by both community group differs according to the compliment type? 


\section{Literature Review}

\section{Studies on Compliment Response (CR)}

Many studies have been conducted examining speech acts in the past decade. These studies have examined the use of speech acts in different languages, especially different variation of English. Compliment response is one of those speech acts which have been studied in English-speaking countries mostly (Pomerantz 1978). Pomerantz's and Herbert's research are the most influential research and the most cited papers in this field which have been used by other researchers as a base, especially by those which have examined this topic across different languages and cultures (Cohen, 1996).

Herbert et al (1989) is the second influential person in this field who conducted an extensive study comparing between compliment and compliment response among American and south African university students. The findings of his work on English and African compliment response strategies showed that the American speakers are less likely to accept a compliment than the English and African speakers; He ended up modifying the Pomerantz's taxonomy of compliment responses to three main categories on the macro level and twelve type sub categories.

It has been demonstrated that studying the compliment response strategies helps in understanding the cultural norms and values as the responders aim at responding to a compliment taking into account the prescribed cultural values in their response. This fact is supported by Tang and Zhang (2009), who conducted a study on CRs between Mandarin Chinese and Australian. They discovered that Chinese speakers preferred not to accept the compliment unlike their Australian counter-parents. Their finding showed that Chinese speakers tended to adopt politeness strategies in their responses unlike the Australian speaker.

In addition to the preceding studies, other researchers, such as Yousefvand (2010), Tarabi, and Beuzeville (2012) reached to a similar result concerning the impact of culture on the frequency of a compliment response. Both studies showed that Persian speakers are more likely to agree with a compliment using modesty in their response. This seems to reflect the impact of their culture on their response. As regards the compliment responses in Arabic culture, in a study by Falasi (2007) who examined how differently Emarati females responded to compliment in Arabic and in English; found out that Emarati females showed an inclination to agree and to use Arabic formulaic expressions in their reply to a compliment in English, since they assumed that the expressions they used to respond to a compliment are universal. 
It has been found that there are several factors influencing the way people respond to compliments. Both Holmes (1988) and Herbert (1990) attributed many of the differences in compliment responses to the gender factor. Further, other social factors such as the status relationship, and the social distance between the complimeter and complimentee have been found to be deceive factors in determining the type of compliment response (Wolfson, 1989).

The object being complimented is considered as another key factor that has an effect on the way people respond to a compliment. Researchers have narrowed down compliment topics to a few main categories. For instance, Wolfson (1981), Holmes (1988), and Manes (1983) who investigated varieties of English - established that compliment types mostly fell into four categories: appearance, possessions, ability, and performance. In a study of English and Chinese compliments, Yu suggested a category of "other" for examples which did not fit well into the other four categories: such as complimenting a person on who they are, as in "I'd sure hate to lose you" (2005, p. 107).

Many researchers such as Creese (1991); Wolfson \& Manes (1980) conducted studies on compliments and compliment responses. Accordingly, many classifications and taxonomies of compliments were proposed. Among those, Manes and Wolfson (1981), Herbert's (1986) Taxonomy of Compliment responses, and Holme's (1986) taxonomy of compliment response are most widely used. Drawing on Herbert's (1986) taxonomy (Appendix5), the present study examines the types of CRs in the two languages. Despite the fact that many cross-cultural studies are conducted on understanding compliment response in both western culture and eastern culture, yet it seems none so far addressed the compliment response in Kurdish culture.

\section{Compliment and politeness}

Despite the fact that the politeness formulae proposed by Brown and Levinson (1987) is estimated to be universal, yet, many scholars acknowledge the possibility of crosscultural variability (Leech, 1983; Sifianou, 1992). Sifianou emphasized, "in general, when we talk about politeness, what we have in mind is relative politeness, based on what we think is appropriate behaviour in particular situations. These norms, however, vary from culture to culture" (1999, p. 29).

It is noteworthy to reflect on the Persian politeness as the researcher of this paper believes that the communicative behavior in Kurdish culture is somehow guided by a politeness system similar to the Persian politeness system, which is intimately tied to a Persian culture-specific behavioral phenomenon called taarof. Taarof is defined by Beeman (1986) as praise and the language of politeness in Persian culture. It is the custom and tradition in Kurdistan as in Iran to care about others more than one's self and 418 | acadj@garmian.edu.krd Vol.5, No.4 (August, 2018) 
not to speak about one's achievements, however, the claim about Kurdish culture need to be tested out more to prove that (Sharifian, 2009).

Underlying this ritual are some Persian culture-specific politeness features which I could claim are similar to the ones accounted for in Kurdish culture such as adab (good manners), ehteram (courtesy, respect), shaxsiat (character-positive face), tavazo (modesty, humility), aberu (roughly synonymous with credit or prestige-implying the concept of face and how people judge a person), and shekasteh-nafsi (literally breaking self, meaning putting oneself down). Not being able to comply with those politeness features when responding to compliment would result to be seen as discourteous, rude, impolite, disgraceful and disrespectful.

\section{Methodology}

\section{Instruments}

Discoure completion tasks (DCTs) are used extensively as the main tool for collecting the data in different research investigating the pragmatic areas of language. Although this method of data collection has been criticized as claimed by (Golato, 2003), yet, there are two major reasons why a DCT was employed as a tool for collecting CRs. Firstly, a DCT helps the researcher to collect adequate pragmatic data within a relatively short time. Second, it allows the researchers to control the variables such as the social status, social distance between the interlocutors thus narrowing down the scope of the research.

Therefore, the data for this study were obtained by the use of DCT consisted of 14 situations in which the complimentees were either inferior or equal to the complimenter and that dealt mainly with everyday life events.

The DCT used in this study was a modified version of DCT which was taken from Tarabi and Beuzeville (2012) who modified Sharifian's (2005) DCT (see appendix 2). The modified discourse completion test consisted of 14 situations requiring the respondents to respond to different compliment topics, particularly five topics such as appearance, skill, performance, possession, and personality. For each topic, 3 situations were used, except for appearance where two situations were used. One question was deleted because it did not fit into Kurdish context when people received compliment on tight dress from the opposite sex and in club. Moreover, as long as the topics and the situations in the modified DCT (complimenting on appearance such as a new hairstyle or abililty such as having a great voice) were found to be scenarios encounterd by both Australian and Kurdish people, thus it was found to be suitable to be used in this study. 
The questionnaire was translated into Kurdish language to be answered by the Kurdish speakers (Sorani dialect) (see Appendix 3).

\section{Participants}

10 Kurdish native speakers contributed to this study of both genders, 4 females and 6 males. All participants were postgraduate students at the University of Nottingham whose native language is Kurdish (Sorani dialect). This group of people was chosen to be involved in this study since they lived in the UK, and they were easy to be accessed to. Besides, since this study was conducted in a foreign setting, the access to Australian English natives were not possible, so, the data related to Australian English native speakers adopted from the previous findings conducted by Tarabi and Beuzeville (2012), so, for the findings to be comparable, the same data collection instrument was employed. The total number of subject in that study was 10 Australian native speakers.

\section{Procedure}

A Kurdish version of the questionnaire was given to Kurdish participants and, after explaining the aim of the study, some of them agreed to be met in their home to fill in the questions. Moreover, the participants were required to answer the questions in a way they normally do in everyday life, while, the rest of participants, around 4, who travelled to another city in the UK, agreed to fill in the questions via Skype, so they could ask any questions that might arise.

After collecting the data, the participants' answers were translated in to English with the help of postgraduate Kurdish students, to be able to compare the Kurdish response strategies to the Australian ones based on the Tarabi and Beuzeville (2012) data. Then, the Kurdish data were analyzed to identify and classify each response strategy based on Herbert et al (1989) classifications then extract the percentage from them (see table 1).The strategies were carefully calculated manually.

\section{Analysis and Discussion}

In this section, the findings from the data were analysed based on Herbert's taxonomy (see Appendix 5). First, each response by the Kurdish participants was calculated to measure the frequency of the occurrence of each response type on the micro and macro level ,then compared to the Australian compliment response strategies presented in Tarabi and Beuzeville (2012)'s paper which are tabulated as presented in the table (1). Then, responses to each question from each participant were coded for the types of compliments being responded to (of the five categories). 
The results from a macro-perspective: in terms of agreement versus non-agreement of responses across all compliment types will be highlighted. Then, I look at how the participants responded to the each compliment type in more detail.

From a macro-pattern perspective, we can see that both groups strongly favored agreement strategies when responding to compliments. However, when analysing those responses that were in the macro category of agreement, it can be seen that the two groups differed in the strategies for agreement used. Between 55-68\% of all agreement responses were categorised as acceptance for both groups.

With regards to non -agreement category, it appeared that Australian speakers favored this category less than Kurdish speakers did. The overall all non- agreement categories produced by Australian speakers accounted for only $8.5 \%$ while Kurdish speakers performed this category $13 \%$.

Interestingly, when looking at the compliment responses using a transfer strategy (see table 1), both group of speakers more commonly returned the compliment force to their interlocutor, whereas the Anglo-Australians more often re-assigned the credit to someone not present. Although only speculation, this may be due to Australian's discomfort with compliments because of the conflict of not disagreeing while maintaining modesty (Herbert, 1986; Pomerantz, 1978).

\section{Micro-analysis by response category}

In order to have a better idea of how the two groups differed, a more in-depth analysis has been carried out on their responses to all compliments. Table (1) shows that overall there are some differences between the groups. As no tests of statistical significance have been carried out, I cannot tell which differences are significant.

\begin{tabular}{|c|c|c|c|c|}
\hline $\begin{array}{l}\text { Macro } \\
\text { categories }\end{array}$ & Macro-Sub categories & Micro categories & Kurdish & Australian \\
\hline \multirow{6}{*}{ 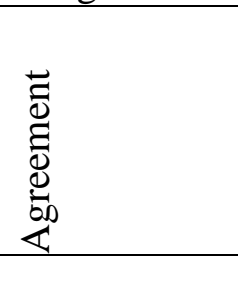 } & \multirow{3}{*}{ Acceptance } & Appreciation & $93(40 \%)$ & $41.2 \%$ \\
\hline & & Comment Acceptance & $30(13 \%)$ & $18 \%$ \\
\hline & & Praise Upgrade & $4(1.7 \%)$ & $1.7 \%$ \\
\hline & Comment History & Comment History & 1 & $6.9 \%$ \\
\hline & \multirow[t]{2}{*}{ Transfer } & Reassignment & $15(6.4 \%)$ & $8.6 \%$ \\
\hline & & Return & $40(17.2 \%)$ & $8.6 \%$ \\
\hline \multirow{4}{*}{ 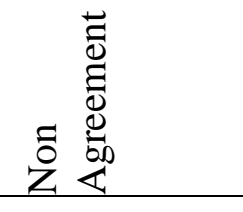 } & Scale down & Scale Down & $19(8.1 \%)$ & $3.0 \%$ \\
\hline & Question & Question & $5(2.1 \%)$ & $2.1 \%$ \\
\hline & \multirow[t]{2}{*}{ Non- Acceptance } & Disagreement & $3(1.3 \%)$ & $3.0 \%$ \\
\hline & & Qualification & $3(1.3 \%)$ & $0.4 \%$ \\
\hline & Non Acknowledgment & Non Acknowledgment & 1 & $4.7 \%$ \\
\hline \multirow[t]{2}{*}{$\begin{array}{l}\text { Other } \\
\text { Interpretation }\end{array}$} & Request & Request & $7(3.0 \%)$ & $0.9 \%$ \\
\hline & Formulaic & & $13(5.6 \%)$ & \\
\hline
\end{tabular}


Table 1: Distribution of responses for each category as a proportion of all responses for that cultural group

According to the figures shown in appendix (1), saying "thank you" or appreciation token was the most preferred response to compliments on appearance, ability, performance, possession, and personality.

It is interesting to note that a comment history was not produced by Kurdish speakers, whereas the Australian speakers did so just fewer than $7 \%$ of the time. In addition, surprisingly, whereas $4.7 \%$ of Anglo-Australians didn't acknowledge a compliment; these Kurdish participants didn't produce this strategy as a compliment response. A possible reason to explain why Australians respond to compliment using less acknowledgment and comment history strategy is that Anglo-Australians endeavor to compromise between maintaining modesty, and avoid rejecting a compliment at the same time. More research is needed in this area to test this hypothesis. Instead, Kurdish speakers seemed to have a strong tendency towards transferring the force of a compliment either to the complimenter or to the complimented object. They returned a compliment to a complimenter $17.2 \%$, whereas $8.6 \%$ of Australians used this response category.

With respect to the non-agreement strategies, on the macro level, Kurdish speakers overall use of this category accounted only for (13\%), Australian, on the other hand used it less than the Kurdish interlocutors did by (5\%).

It is interesting to note that Kurdish participants attempted to mitigate their compliment response $(8.1 \%)$ more often than the Australians did which made up only $3 \%$.

The following examples will illustrate the responses employed by Kurdish speakers using one kind of non-agreement category

A Kurdish person compliment response on his or her ability /skill such as their cooking was as folllows: "Aafytt bet, min chesht lener bash nim". Hope you have enjoyed it; I am not a great cook.

Another example of disagreement strategy was produced while responding to compliment by a friend.

Na wanya,to zor bashi, xamt nabi agaman laek abe (No, you are a nice person, don't worry we will be in touch)

Regarding the response category known as "other interpretation" which includes request as one of the compliment strategies, both Kurdish and Australian speakers tended to use 
it in their response to a compliment, but Kurdish participants seemed to opt to this strategy more than Australian participants.

By analyzing the strategies within agreement categories on the micro level, the results revealed that irrespective of the appreciation token as the most frequently used strategy by both groups, the comment acceptance strategy was the second preferred strategy by both groups. The comment acceptance strategy seemed to be used by both groups alike, but Kurdish speakers showed a higher tendency in producing this strategy. This finding corresponds with Yousefvand's (2010) findings who found out that Persians tended to use comment acceptance as a way of avoiding self-praise. The results showed that both Kurds and Australians showed a great tendency towards accepting the compliment in a way which kept them from praising themselves by reassigning and returning the compliment to the complimentee, especially when they received a compliment on their appearance and their personality.

The return strategies which were used by Kurdish participants occurred in the form of formulaic expressions which appear to be specific only to Kurdish culture when they said, for instance, "chawt jwana" which can be interpreted as "your eyes are beautiful".

Kurdish people, instead of accepting a compliment in a more direct way tended to use formulaic expressions such as "Aafettt bet" (hope you enjoyed it, or bon appetite) or "nukhshat le bet" (wish you the same). These responses, as Yousefvad (2010) claimed, could be rooted in the Kurdish culture and they enable the addressee to hide their embarrassment by using those expressions.

It is also evident that those formulaic expressions were produced when Kurdish people tried to disagree indirectly with the compliment targeted to them, and used as a substitute to directly replying with "no" which might be seen as a face threatening by the addresser. This finding seems to be in agreement with Leech's Modesty Maxi (1983), that the receivers of a compliment tend to express their modesty by using an alternative strategy rather than using the direct one.

Praise upgrade is one of those strategies, which had a low frequency for both group of speakers, Australian used it when they responded to a compliment on their child, while Kurds seemed to use it in a humorous way when they responded to a compliment on skills. Another interesting response by Kurdish speakers is the use of some cultural norms in their response on a performance. 


\section{Responses for compliments on appearance}

Approximately half of the respondents from both groups responded with an appreciation token to start their response for compliments on appearance.

As it can be noticed from Figure (3 and 4) in Appendix(4), Anglo-Australians used reassignment in response to appearance compliments less frequently than the Kurdish people did. Australian females in particular had a higher tendency to use reassigning strategies wherever possible, compared to Kurdish females. In the case of "new haircut" in which a third party could be imagined by the participants; For this scenario, most of the Anglo-Australian females attempted to directly reassign the compliment to the hairdresser by saying, for example, "my hairdresser Ross does a good job"; however, Kurdish females usually responded with a question and return the compliment to the complimenter, for instance "Your eyes are beautiful; it would be nicer on you if you had the same hairstyle". The Anglo-Australian and Kurdish males, on the other hand, had more similar patterns of distribution for reassignment, questioning and as in "I just got it done for $20 \$ "$, or as the Kurdish male speaker said the hairdresser did the great job.

\section{Responses for compliments on a skill, ability, or talent}

For compliments of skill, ability or talent, both Australians and Kurdish tended to reassign, and return the complimentary force where possible, as they did for compliments on appearance. For example, in responding to a compliment on cooking, many Anglo-Australians attributed the complimentary force to the recipe, and for a compliment on handwriting to their mother.

Moreover, Kurdish speakers attempted to mitigate the force of compliment and by downgrading their own potentiality. This could be attributed to the fact that Kurdish speakers try to avoid describing themselves and using "I".

This could be interpreted in the light of shekasteh-nafsi schema which restricts Iranian speakers from describing themselves and it explains the reason behind Kurdish speakers refrain from using one's "I" and discussing their achievements to avoid self-praise (Sharifian, 2005).

Australians preferred to reassign the compliment being paid on their skills, for example, they reassigned the complimentary force of a compliment on their cooking ability to the complimenter, and this strategy on the other hand used less by Kurdish speakers. When comparing the responses made by both groups on skill topics in terms of power relation. The results showed that Kurds tended to use some formulaic expressions such as"bzhet" which can be interpreted as "long live you" and "barezet" which could be interpreted as "you are a respectable person"; to respond to a compliment given either by a teacher or their mother. This illustrates how Kurds are aware of politeness theory and 424 | acadj@garmian.edu.krd Vol.5, No.4 (August, 2018) 
try not to threaten the face of the interlocutor who might not have the same status level as they do. On the other hand, Australians did not appear to employ such norms in their culture when they didn't show preferences in using acceptance or the above-mentioned expression in their response to a teacher.

"هيجم " Moreover, Kurdish speaker were more likely to use formulaic expression such as "نووشى كيانت بى", to show a high degree of modesty and avoid praising themselves. This could be construed in the light of the cultural schema of shekastehnafsi, and is in line with what Sharifian illustrated with respects to the construction ghabel nistim in Persian languange, which means, "we are not worth it" (2007, p. 44), and they put themselves down by using other expressions like "I don't think my food is cooked well".

\section{Responses for compliments on performance or achievement}

The data in table 2 and figure $(1,2)$ in Appendix (1) showed that there is a similarity in using transfer strategies in response to performance compliments by both Australian and Kurdish speakers, however, there is a difference based on the power differential between the complimenter and the responder. In the scenarios based on performance or achievement, the compliments were given by a teacher, a mother and a friend. Overall the results look similar, when looking at the single scenarios, the Kurdish speakers would respond to a friend compliment on their achievements with comment acceptance or reassignment, however, they would never use comment acceptance in their response to compliment on their achievements by a teacher or their mother. They either tried to return the force of compliment to their mother and teacher, For instance, they responded to their mum saying" سوياس دايه كيان، ئهوه بهرهمى توّيه" (Thanks Mum, I achieved that because of your efforts) or attempted to mitigate the compliment and use scale down strategy for example, a male Kurdish speaker response to teacher compliment on his " achievement was as "That is my duty, I haven’t done anything" ئه وه ئه ركى منه ماموستا، هيجم" نهكردوه This could reflect the effect of social factors, such as position, power and solidarity on the choice of compliment responding strategies. Anglo-Australians, on the other hand, showed more inclination to accept the performance compliment given by a teacher. This implies that the people in Kurdish culture tend to employ the politeness strategy and not to accept the compliment directed to them explicitly. Australian people, unlike Kurds, who never responded to a compliment giving background information on the complimented object, appeared to be inclined to use a comment history strategy. Kurdish speakers used expressions such as "awa arke mina" which can be interpreted as "it is my duty" when they received a compliment by a teacher. In contrast to their 
response to a friend, they tended to interpret it as a request for staying in touch in the scenario when a Kurd participant was given a compliment on his personality.

These dissimilarities explain how the cultural conceptualizations of social relations become evident in language choices. Further research on a larger pool and examining the effect of social variables would illustrate the issue more.

Several examples are provided to better illustrate the situation; when a Kurdish speaker received a compliment on the cleverness of his or her child by a friend and he or she responsed as: "zor supas Xwa danayaki wash bda ba to" (Thanks a lot, May God bless you with a child like this). And the Australian respondent responded as follows

I am not sure about that, but she has some other great strengths.

\section{Responses for compliments about possessions or belongings}

With respect to responses on possession, most of the Australians opted to avoid the force of a compliment directed to them and they showed an inclination toward the use of the disagreement strategy, downgrading the force of a compliment. Examples of this type are:

Scale Down to the compliment "You have a very nice car".

Anglo-Australian: Thank you. It's leased!

Disagreement to "You have a very smart child". Anglo-Australian: I am not sure about that, but she has some other great strengths.

However, Kurdish people tended to either answer using a return or request strategy. It is noteworthy, as Tabari and Beuzeville (2012) noted, that Herbert (1986) included this strategy "other interpretation request" in his classification which reflects that the recipient of a compliment interprets the compliment as "request" rather than compliment. Further, it could be claimed that Kurdish people, as Persian speakers did in Tabari and Beuzvelle (2012), inclined towards offering the complimented object not because they interpreted the compliment as a request, but rather appeared to behave in accordance with the norms which are specific to their culture known as "Taroof".

Kurdish speakers employed the formulaic expression like "your eyes are beautiful" in order to return the compliments (in the case of "a new car") or "[the] presence of friends makes it much more beautiful for me"(in the case of a new house).

Kurds participants used another formulaic expressions such as "Nuxshat le be" which means in English "wishing or hoping that the complimenter gains a similar object" in this context when responding to compliment on possession. More specifically, in some responses, this expression was used as a plea where God is asked to help the complimenter to get the object, or to grant them with a child of their own. This finding coincides with the result reached by Yousefvad (2010) that the belief, the norms, and the 426 | acadj@garmian.edu.krd Vol.5, No.4 (August, 2018) 
religious background of Kurds, Persian, and Arabic are reflected in their responses. Thus, they tend to mention the Name of God in their response to a compliment.

Both groups also used praise upgrade. However, their intention for using it appeared to differ. Only two Kurdish participants employed praise upgrade, but they appeared not to be genuine and don't literally mean it, in order to redress the force of the compliment. However, Australian speakers upgraded the force of compliments given to their car genuinely .The examples below can imply these different intentions.

A: you have a very smart child!

B: It's in our genes! (haha)

A: you have a very nice car!

B: we should go for a drive so you could see and feel the performance. It is great!

\section{Responses for compliments on personality}

Anglo-Australians acknowledged and returned compliments on personality less than Kurdish speakers did. Anglo-Australians, on the other hand, mostly tended to evade the force of compliment by ignoring the main compliment, when possible. For example, in reply to the compliment, "what am I going to do without you?! I'll hate not having you around! You're such a good friend!" most of the Australians responded only to the first part "what am I going to do without you?" as if to find a way to solve this problem and did not acknowledge the main compliment "you are such a good friend". Some examples of responses are:

Anglo-Australians:

- OK, I'll email you and anyway, I'll be back soon.

Kurdish speakers:

- You are sweet, I will not forget you, and we will be in touch

- Thanks, this is because you are a nice person that is why you think I'm good.

Most Kurdish speakers employed acknowledgement strategy and responded the main compliment by an appreciation token and return. This explains the fact that Persians are more accustomed to and comfortable with compliment speech act and responding to compliments than Anglo-Australians.

Nevertheless, there are some remarkable findings concerning some strategies, which are not mentioned in the above discussion.

\section{Conclusion}

As a summary, the findings have shown that the compliment responses of Kurdish participants and those in Australia did differ; the results revealed that both groups 
preferred agreement than any other strategies. Within agreement strategy, while Kurds more often returned the compliment to their interlocutor than the Australian speakers did. However, there were ways in which the two groups performed more similarly to each other: for example they were less likely to praise and accept the compliment.

Patterns of agreement were similar for the speakers residing in Australia and those living in Kurdistan. However, commenting on the history of the complimented object was only employed by Australian speaker, and unlike Kurdish speakers they returned a compliment less often.

Moreover, the result has revealed that the Kurdish speakers are inclined towards mitigating the force of compliment on certain type of compliment more than the Australian did. Further, Kurdish speakers disagreed to a lesser degree than the Australian did.

Some of the differences have also been found which reveal how each culture tends to incorporate their cultural norms in their interaction. The Kurds, for example, have used some formulaic expressions attempting to link the response of the compliment directed to them to their religion, especially when they were complimented on their performance. Additionally Kurds were inclined to applying the politeness strategy they follow in their culture to the response to some of the compliment topics such as the skill topic.

So, although, the data presented here are based on a small sample size, what does this level of difference reflects is that communicative behavior in each culture is foregrounded by the values, politeness system and social variable of that culture. By teaching pragmatic and the sociolinguistic aspects of the target language, ESL/EFL teachers can help learners in the new community use socially appropriate language in their interactions with the native speakers in a shorter period of time. As it can be seen from the results of this research, the cultural norms have an effect on the speakers' choice of language. Research of this type, assists in both, to be used as guidelines for ESL pedagogical purposes, and to raise the awareness of speakers of a language and of their different sociocultural and pragma-linguistic norms.

\section{References}

Al Falasi, H. (2007). Just say thank you: A study of compliment responses. The Linguistics Journal, 2(1), 28-42.

Austin John, L. (1962). How to do things with words. Clarendon Press, Oxford3. Bach $K$ (1998) Speech acts. In: Craig E (ed) Routledge Encyclopedia of Philosophy. Routledge, London4. Clark H, Brennan S (1991) Grounding in communication. Pers Soc Psychol Rev, 13, 127149.

Beeman, W. O. (1986). Language, status, and power in Iran. Indiana University Press. 
Brown, P., \& Levinson, S. C. (1987). Politeness: Some universals in language usage (Vol. 4). Cambridge university press.

Chang, Y. (1988). Compliments in Chinese Contexts. Unpublished manuscript, University of Illinois at Urbana-Champaign.

Creese, A. (1991). Speech Act Variation in British and American English.

Daikuhara, M. (1986). A study of compliments from a cross-cultural perspective: Japanese vs. American English. Working Papers in Educational Linguistics (WPEL), 2(2), 6.

Golato, A. (2003). Studying compliment responses: A comparison of DCTs and recordings of naturally occurring talk. Applied linguistics, 24(1), 90-121.

Golato, A. (2005). Compliments and compliment responses: Grammatical structure and sequential organization (Vol. 15). J. Benjamins Publishing Company.

Herbert, R. K. (1986). Say" thank you"-or something. American speech, 61(1), 76-88.

Herbert, R. K. (1990). Sex-based differences in compliment behavior 1. Language in society, 19(2), 201-224.

Herbert, R. K., \& Straight, H. S. (1989). Compliment-rejection versus complimentavoidance: Listener-based versus speaker-based pragmatic strategies. Language \& Communication.

Holmes, J. (1988). Paying compliments: A sex-preferential politeness strategy. Journal of pragmatics, 12(4), 445-465.

Leech, G. (1983). N., 1983, Principles of Pragmatics, London and New York.

Manes, J. (1983). Compliments: A mirror of cultural values. Sociolinguistics and language acquisition, 5(3), 96-106.

Manes, J., \& Wolfson, N. (1981). The compliment formula. Conversational routine: Explorations in standardized communication situations and prepatterned speech, 96.

Motaghi-Tabari, S., \& de Beuzeville, L. (2012). A contrastive study of compliment responses among Persians and Australians: The effects of exposure to a new speech community. Applied Research in English, 1(1), 21-42.

Nelson, G., Al-Batal, M., \& Echols, E. (1996). Arabic and English compliment responses: Potential for pragmatic failure. Applied linguistics, 17(4), 411-432.

Pomerantz, A. (1978). Compliment responses: Notes on the co-operation of multiple constraints. In Studies in the organization of conversational interaction (pp. 79-112).

Sharifian, F. (2005). The Persian cultural schema of shekasteh-nafsi: A study of compliment responses in Persian and Anglo-Australian speakers. Pragmatics \& Cognition, 13(2), 337-361.

Sharifian, F. (2009). On collective cognition and language. In H. Pishwa (Ed.), Language and Social Cognition: Expression of Social Mind (pp. 35-44). Berlin: Mouton de Gruyter.

Sharifian, F. (2011). Cultural conceptualisations and language: Theoretical framework and applications (Vol. 1). John Benjamins Publishing. 
Sharifian, F., \& Palmer, G. B. (Eds.). (2007). Applied cultural linguistics: Implications for second language learning and intercultural communication (Vol. 7). John Benjamins Publishing.

Sifianou, M. (1992). The use of diminutives in expressing politeness: Modern Greek versus English. Journal of pragmatics, 17(2), 155-173.

Sifianou, M. (1999). Politeness phenomena in England and Greece: A cross-cultural perspective. Oxford Linguistics.

Tang, C. H., \& Zhang, G. Q. (2009). A contrastive study of compliment responses among Australian English and Mandarin Chinese speakers. Journal of Pragmatics, 41(2), 325-345.

Wolfson, N., \& Manes, J. (1980). The compliment as a social strategy. Research on Language \& Social Interaction, 13(3), 391-410.

Yousefvand, Z. (2010). Study of compliment speech act realization patterns across gender in Persian. Arizona Working Papers in SLA \& Teaching, 17(1), 91-112.

$\mathrm{Yu}$, M. C. (2003). On the universality of face: Evidence from Chinese compliment response behavior. Journal of pragmatics, 35(10-11), 1679-1710.

Yuan, Y. (2001). An inquiry into empirical pragmatics data-gathering methods: Written DCTs, oral DCTs, field notes, and natural conversations. Journal of pragmatics, 33(2), 271-292. 
Appendix 1:

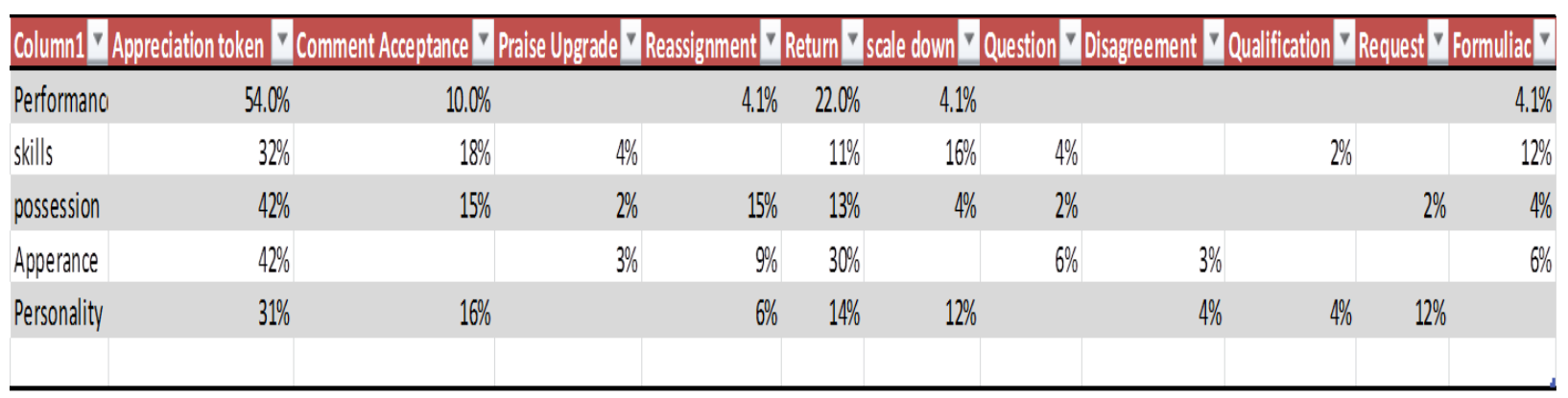

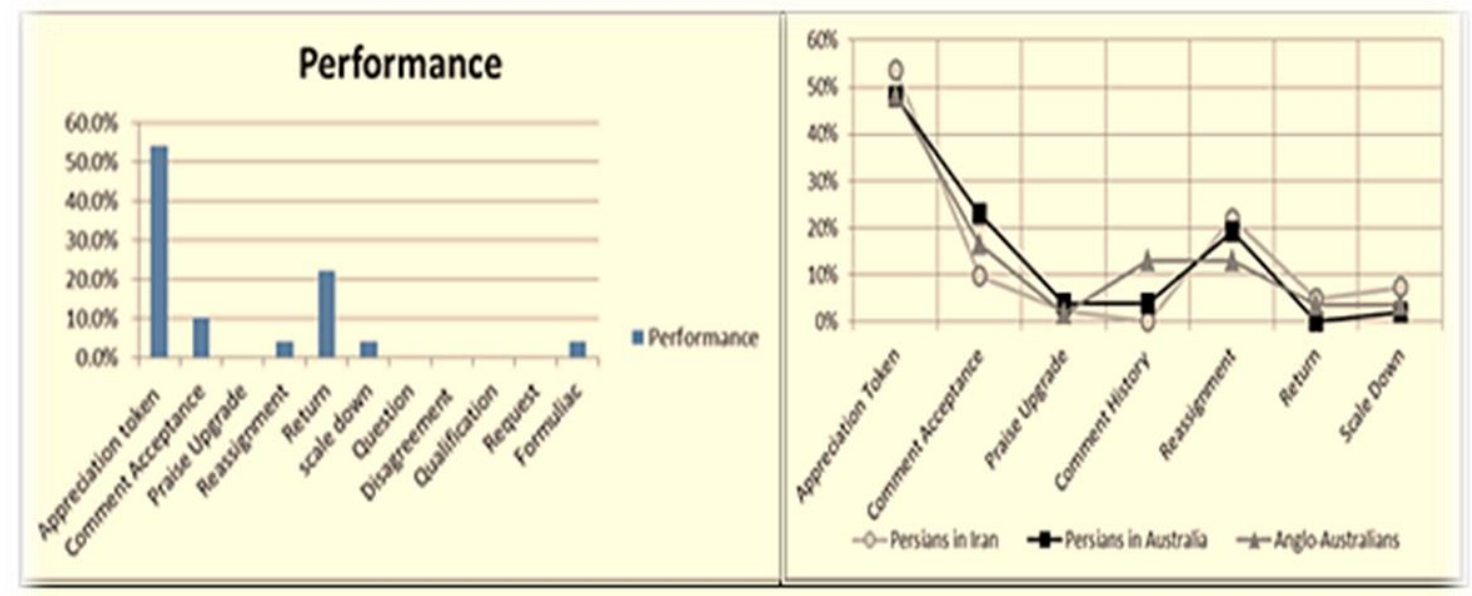

\begin{tabular}{|l|l|}
\hline Figure 1: Micro-analysis of compliment responses for & $\begin{array}{l}\text { Figure 2: Micro-analysis of compliment responses for } \\
\text { performance/achievement compliment types by Kurd ish speakers } \\
\text { performance/acbievement compliment types by Australian } \\
\text { and other two groups }\end{array}$ \\
\hline
\end{tabular}

Appendix 2

You are invited to imagine yourself in a situation where you are being complimented and write down what you would say back to the compliments.

1. You have recently made an impressive achievement such as passing the University Entrance Examination and you come across one of your previous teachers. He/She is so happy to hear the news and congratulates you on your success as follows: Congratulations! You did a great job. Well done!! 
2. A family friend compliments your cooking after dinner by saying "Your food is so delicious. You're a fantastic cook!"

3. Your friend praises your child by saying, "You have a very smart child".

4. Your friend is visiting your newly built house and says, "What a beautiful house!"

5. You have bought a brand new car. Your friend likes your car and says to you, "You have a very nice car!"

6. After reading your essay, your friend/classmate says to you, "You're very intelligent and knowledgeable!"

7. You have received a prize for your outstanding work and your mother says to you, "Congratulations! Well done!"

8. You have an admirable talent such as a very good handwriting or a

Beautiful voice and a friend says to you, "What beautiful handwriting!/What a beautiful voice!"

9. You have recently had your hair cut. A friend says to you, "What a beautiful hair cut!! It is just perfect on you!!"

10. You have had a coffee and chat with one of your friends in a coffee shop. Your friend says, "it's always good to talk to you!!"

11. You are attending a party. A friend (of the same gender) says, "How good/beautiful you look tonight!!"

12. You are going to a trip. One of your friends says "What am I going to do without you?! I'll hate not having you around! You're such a good friend!"

13 You clean the whiteboard for your teacher for a few times. Your teacher says "Thank you! You're so kind/caring!"

14. You win a competition in your favourite sport. Your friend says, "Well done! You did a great job

\section{Appendix 3}

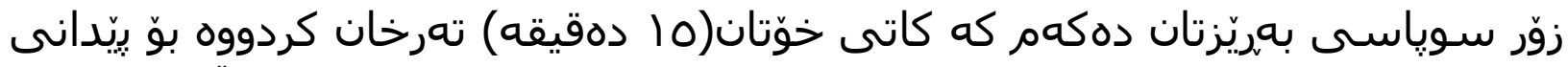

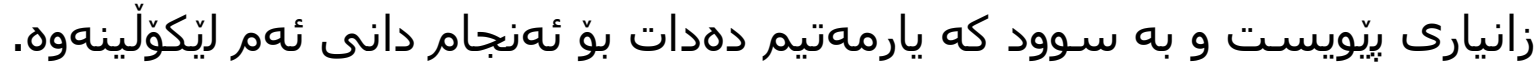

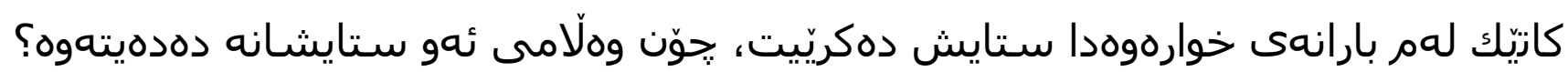

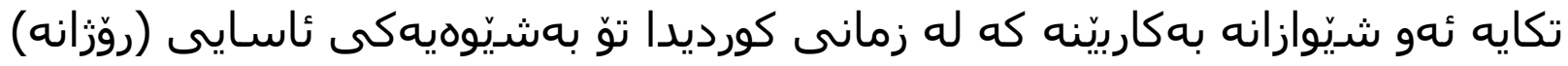
بهكاريان ئههيْنى. 


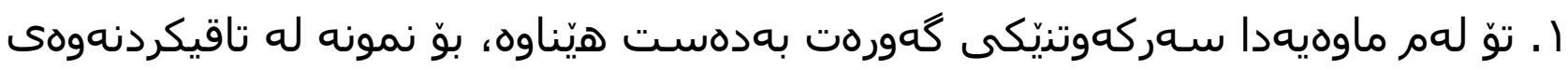

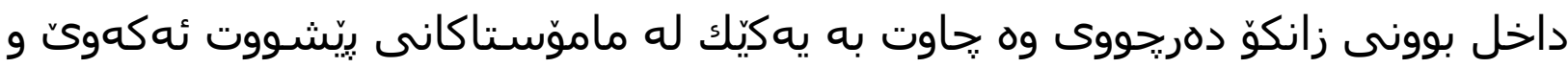

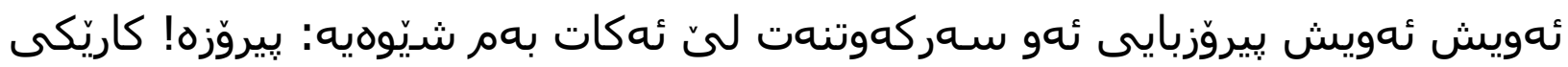

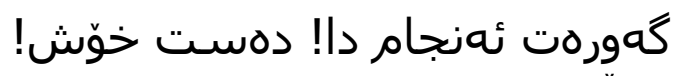

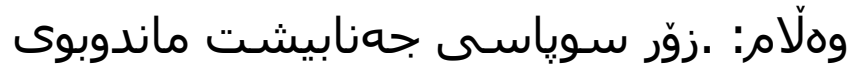

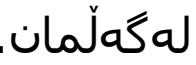

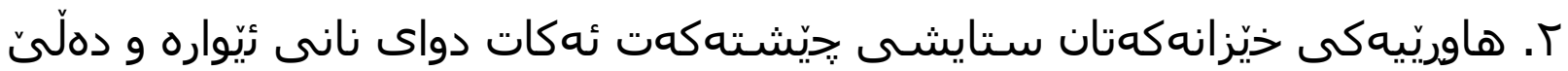

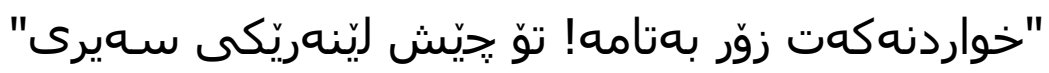

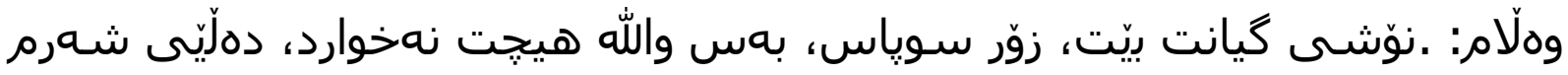

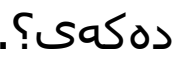

ז. هاوريّكهت ستايشـى مندالّكهت ئهكات به وتنى، "توّ منالِّيكى زوّر زيرهكت ههيه"

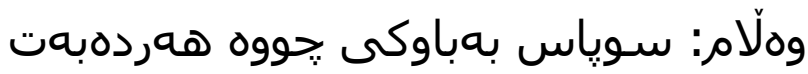

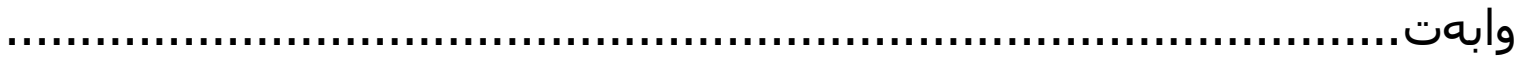

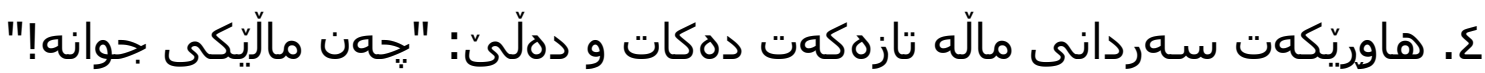

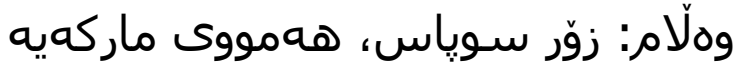

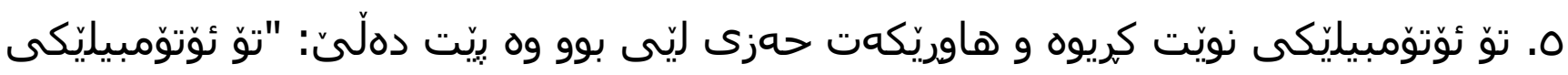

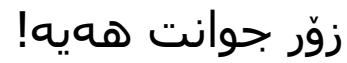
وهلامر: قوربانى توّم، بهس وهوك ئهوهى تو

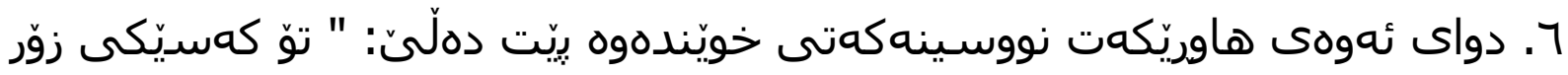
بليمهت و بهزانياريت! وهلام: سـوياس، يهكجا واش 


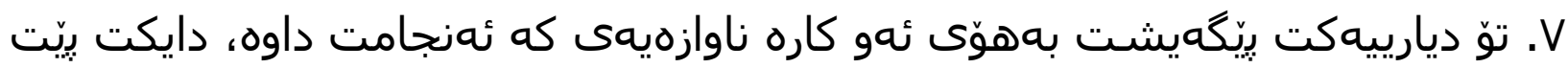

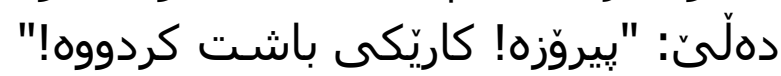

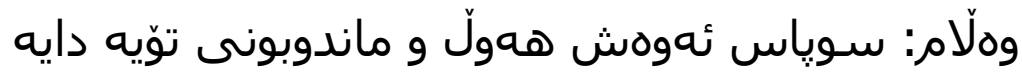

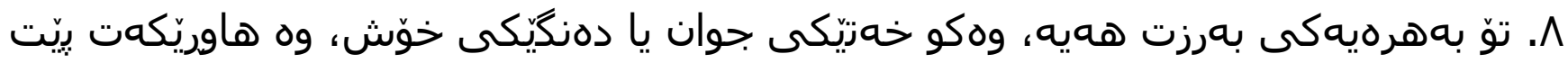

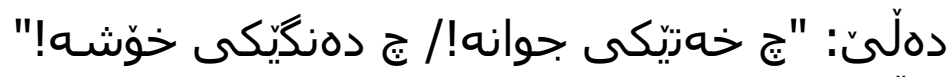

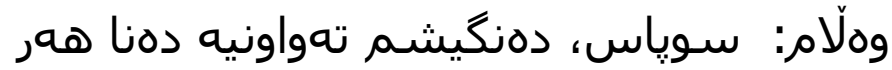
شازه.

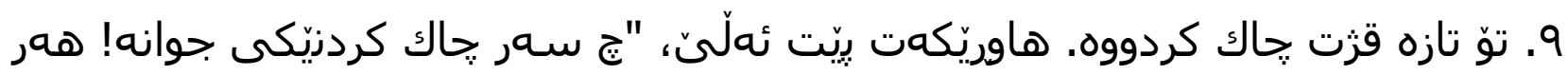

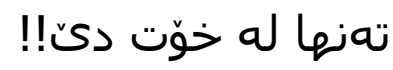

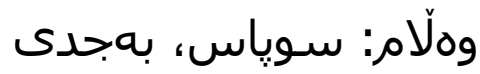
جوانه؟!...

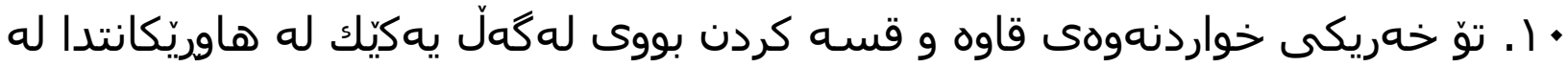

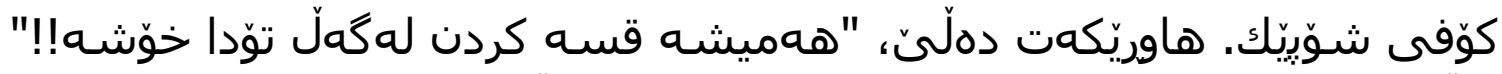

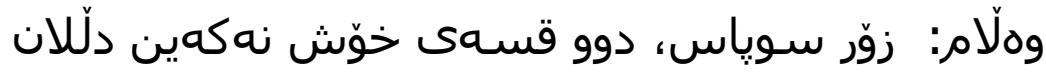

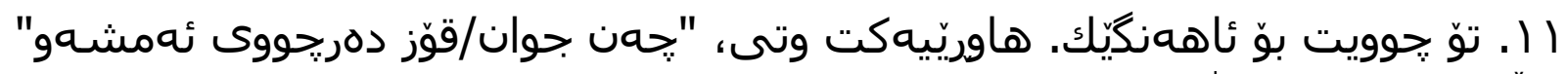

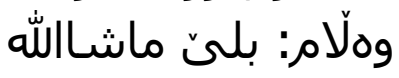

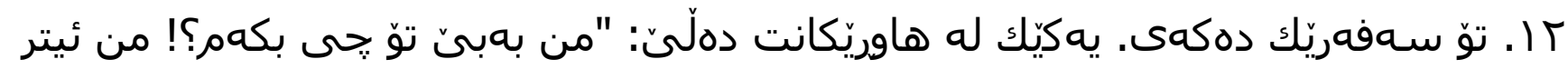

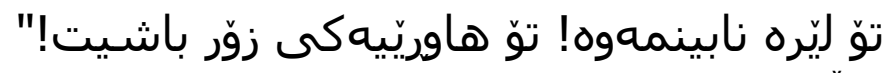

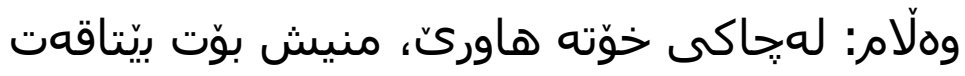
دסبم.

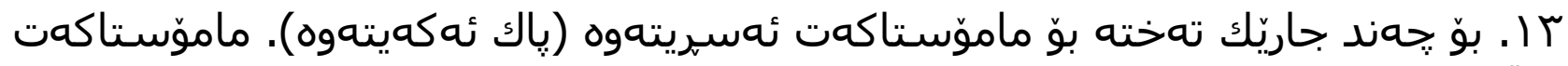

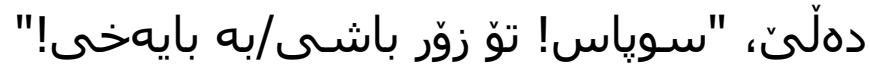




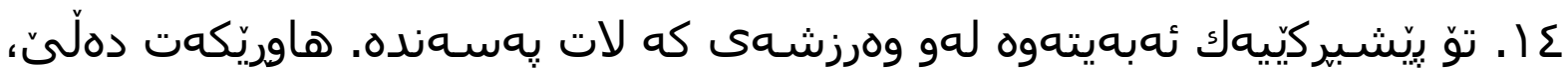

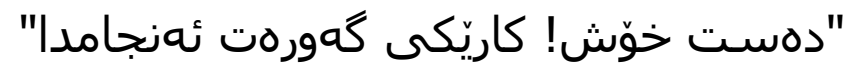

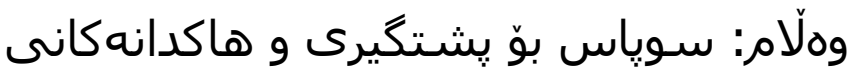

زوّر سوياس

\section{Appendix 4}

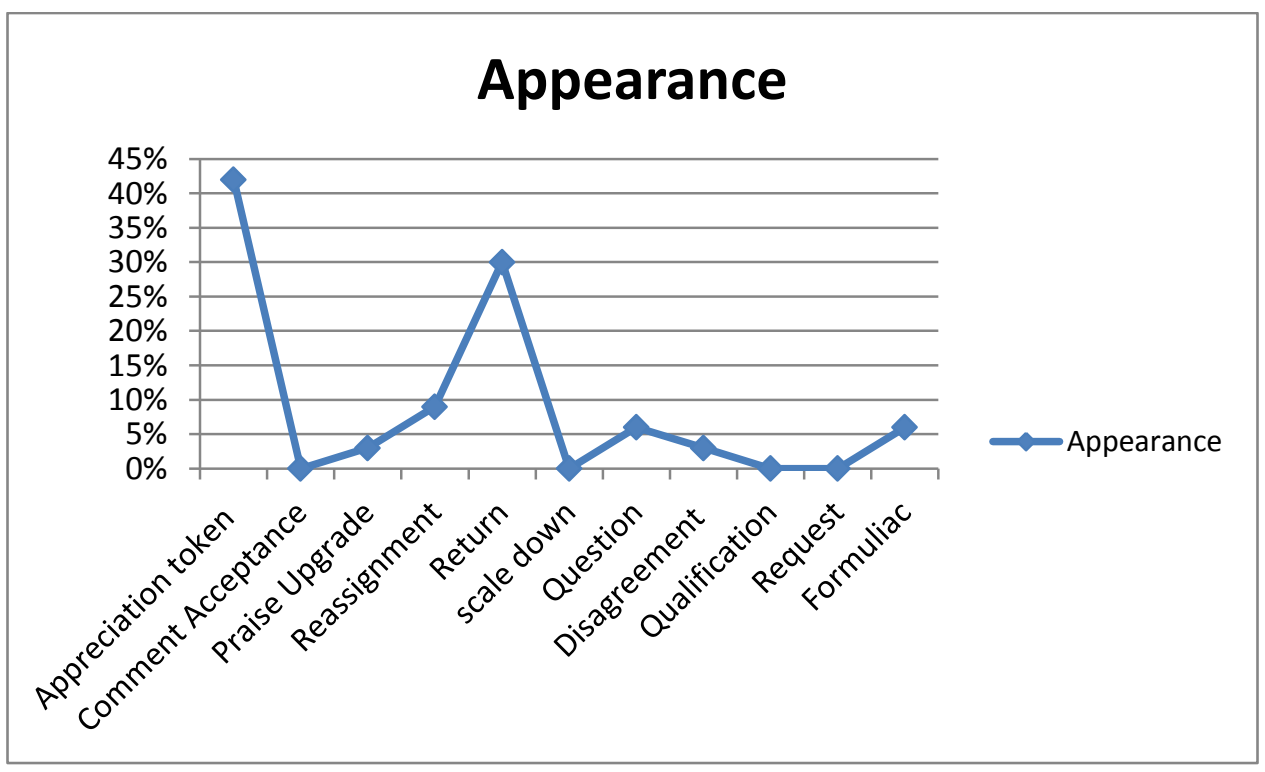

Figure 3: Micro analysis of compliment responses for appearance topics by Kurdish speakers 


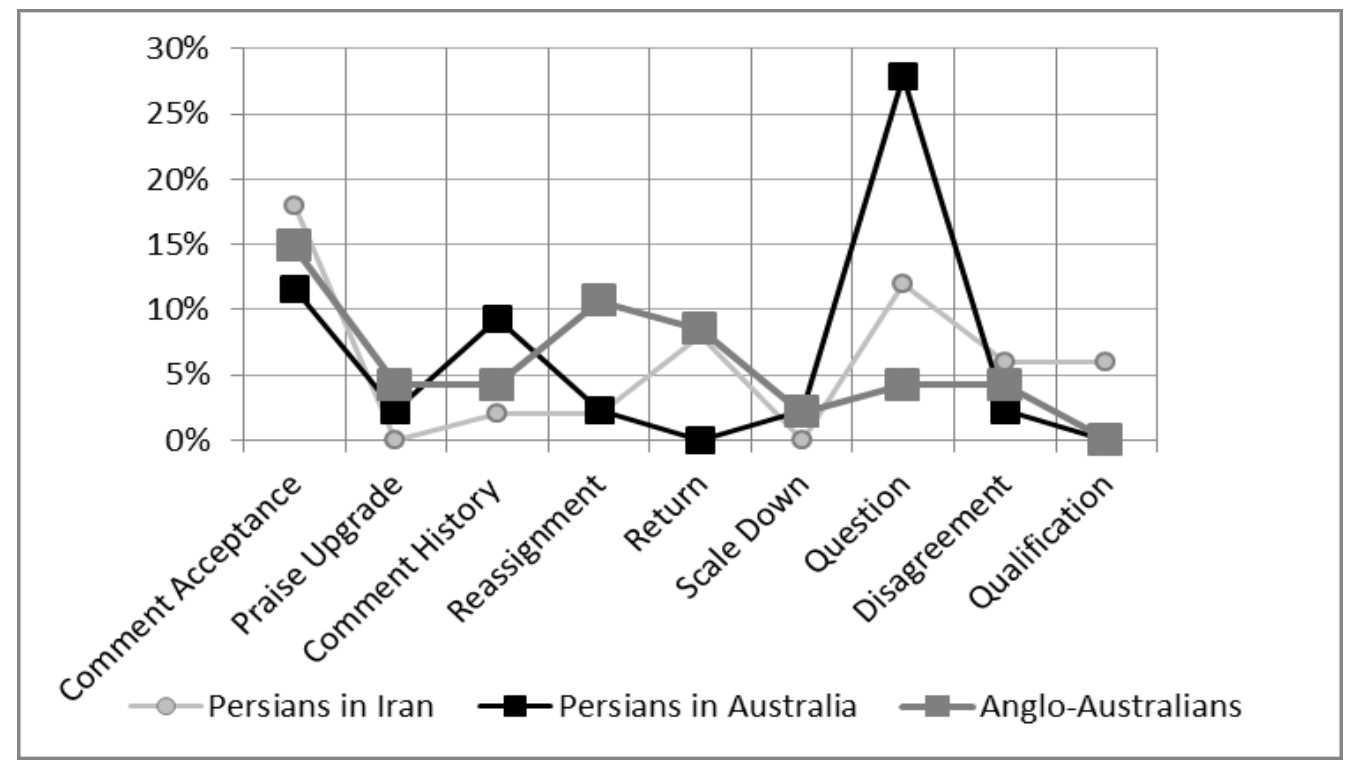

Figure 4: Micro analysis of compliment responses for appearance topics by Australian and other two group of speakers

\section{Appendix 5}

Table 1: Herbert's taxonomy of compliment responses (Herbert, 1986, p. 79), modified by the Tabari and, Beuzeville (2012)

\begin{tabular}{|c|c|c|}
\hline Macro-Categories & Micro-Categories & Examples \\
\hline \multirow{8}{*}{ 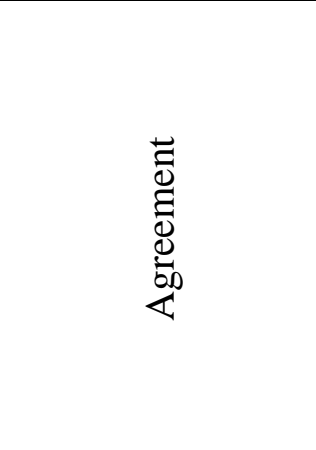 } & Acceptance & \\
\hline & Appreciation Token & Thank You [smile] \\
\hline & Comment acceptance & Thanks, it's my favorite too. \\
\hline & Praise upgrade & It brings out the blue in my eyes, doesn't it? \\
\hline & Comment History & I bought it for the trip to Arizona. \\
\hline & Transfers & \\
\hline & Reassignment & My brother gave it to me. \\
\hline & Return & So's yours. \\
\hline \multirow{6}{*}{ 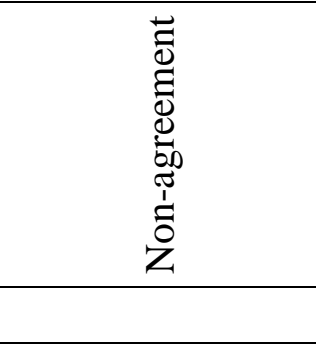 } & Scale down & It's really quite old. \\
\hline & Question & Do you really think so? \\
\hline & Non-acceptance & \\
\hline & Disagreement & I hate it. \\
\hline & Qualification & It's all right, but Len's is nicer. \\
\hline & Non-Acknowledgment & [silence] \\
\hline Other & Request & You wanna borrow this one too? \\
\hline
\end{tabular}




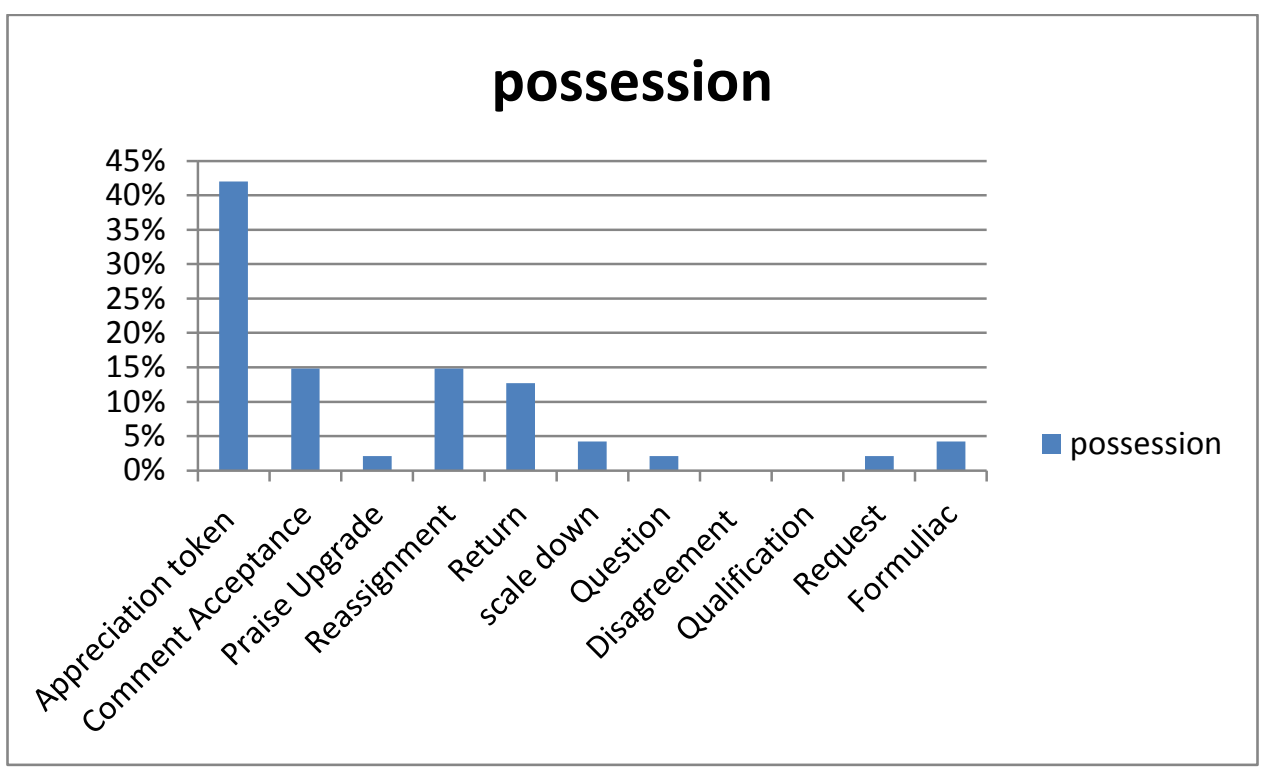

Figure 9: Micro-analysis of compliment responses for Possession compliments types by Kurdish Speakers 